\title{
Optimization method for quantitative calculation of clay minerals in soil
}

\author{
Libo Hao, Qiaoqiao Wei, Yuyan Zhao*, Jilong Lu and Xinyun Zhao \\ Department of Geochemistry, Jilin University, Changchun 130026, China. \\ *Corresponding author. e-mail: zhaoyuyan@jlu.edu.cn
}

Determination of types and amounts for clay minerals in soil are important in environmental, agricultural, and geological investigations. Many reliable methods have been established to identify clay mineral types. However, no reliable method for quantitative analysis of clay minerals has been established so far. In this study, an attempt was made to propose an optimization method for the quantitative determination of clay minerals in soil based on bulk chemical composition data. The fundamental principles and processes of the calculation are elucidated. Some samples were used for reliability verification of the method and the results prove the simplicity and efficacy of the approach.

\section{Introduction}

Clay minerals are major components of soil, their types and amounts are influenced by several factors, such as climate, topography, vegetation, and bedrock type. Clay minerals are excellent tracers of weathering processes of bedrock, especially some typical clay minerals, such as kaolinite, montmorillonite, and illite (Griffi 1968; Fateer 1969; Tang et al. 2002). Moreover, the types and amounts of clay minerals are considered as important constraints on the physical and chemical properties of soil. Quantitative knowledge of the clay minerals is an important index in geological survey, agricultural production, and environmental assessment (Baldock and Skjemstad 2000; Lichner et al. 2006; Brennan et al. 2014). Many reliable methods have been established to identify clay mineral types (Chung 1974a, b; Liao 1995; Wu 1994, 1996), such as X-ray powder diffractometry, differential thermal analysis (DTA), and infrared analysis (IR). However, no reliable method for quantitative analysis of clay minerals has been established so far. Since the 1960s, X-ray diffraction analysis has been a useful tool for quantitative analysis of clay minerals. This method is based on the relation between diffracted intensity and concentration of clay mineral. The contents of clay minerals are calculated by comparison with intensities yielded by standard samples with known components. The analytical uncertainties can be influenced by many factors, such as the choice of standard sample, the sample preparation technique, and the interference due to other minerals present in the sample. Consequently, this method is semi-quantitative (Mitchell 1993; Ding and Zhang 2002; Zhang and Fan 2003). Furthermore, this method can only determine the relative amounts of clay minerals in soil samples. As it is more difficult to quantify non-clay minerals in soil (Singh and Agrawal 2012), it is far less likely to obtain a high precision result. Some researchers have tried to calculate the amount of clay minerals based on their molecular formulae (Chen and Han 1998), or by the method of solving mass balance equations (Li and Li 1995). However, both the methods are obviously defective. While the former suffers from random variation of analytical results, the latter does not provide a unique solution. In our research, a linear programming model was adopted to determine the amount of clay minerals in soils

Keywords. Calculation method; clay minerals; soil; mineral composition; chemical composition; optimization method. 
on the basis of data on soil chemical analysis. This method is simple, has relatively less interferences in the procedure, and higher precision.

\section{Basic principles}

The mineralogical constitution of soil is rather complex. Soil generally consists of primary minerals (e.g., quartz, feldspar), secondary minerals (e.g., kaolinite, montmorillonite, and illite), carbonate minerals, Fe-Mn-colloids, and minor amount of organic matter. The types and amounts of minerals in soils from different regions vary greatly. However, each mineral commonly comprises a group of oxides, though some of them may show heteromorphism. If the soil sample consists of $n$ different minerals, the chemical composition of the sample can be expressed as the following equation:

$$
\sum_{j=1}^{n} A_{i j} X_{j}+\Delta_{i}=b_{i}
$$

where $X_{j}$ is the content of mineral $j$ in soil sample, $A_{i j}$ is the content of oxide $i$ in mineral $j, \Delta_{i}$ is the residual error of oxide $i$ (including analytical errors, etc.), and $b_{i}$ is the content of oxide $i$ (e.g., $\mathrm{SiO}_{2}, \mathrm{Al}_{2} \mathrm{O}_{3}$, and $\mathrm{K}_{2} \mathrm{O}$ ) in soil sample.

The residual error $\Delta_{i}$ can be either positive or negative, so we make $\Delta_{i}=\alpha_{i}-\beta_{i}$, where $\alpha_{i}, \beta_{i} \geq 0$ ( $\alpha_{i}$ is negative residual error, $\beta_{i}$ is positive residual error). The values for mineral contents in soil cannot be negative, which is a constraint. If there are $n$ minerals in a soil whose composition can be expressed in terms of $m$ oxides, equations can be written as:

$$
\begin{aligned}
& A_{11} X_{1}+A_{12} X_{2}+\cdots+A_{1 n} X_{n}+\alpha_{1}-\beta_{1}=\mathrm{SiO}_{2} \\
& A_{21} X_{1}+A_{22} X_{2}+\cdots+A_{2 n} X_{n}+\alpha_{2}-\beta_{2}=\mathrm{Al}_{2} \mathrm{O}_{3} \\
& A_{m 1} X_{1}+A_{m 2} X_{2}+\cdots+A_{m n} X_{n}+\alpha_{m}-\beta_{m}=b_{m} \\
& X_{1}, X_{2}, \ldots, X_{n} \geq 0 \\
& \alpha_{1}, \alpha_{2}, \ldots, \alpha_{m} \geq 0 \\
& \beta_{1}, \beta_{2}, \ldots, \beta_{m} \geq 0
\end{aligned}
$$

Our objective now is to obtain the estimated values of $\alpha_{i}$ and $\beta_{i}$ for which $z=\sum_{i=1}^{m}\left(\alpha_{i}+\beta_{i}\right)$ is the lowest. Then, we can use the optimization method with linear programming to solve the problem.

Taking $\alpha_{i}$ and $\beta_{i}$ as $X_{n+2 i-1}$ and $X_{n+2 i}$, equation (2) can be written in the normal form of linear programming:

$$
\begin{aligned}
& \min z=\sum_{i=1}^{m}\left(X_{n+2 i-1}+X_{n+2 i}\right) \\
& A_{11} X_{1}+A_{12} X_{2}+\cdots+A_{1 n} X_{n}+X_{n+1}-X_{n+2}=\mathrm{SiO}_{2} \\
& A_{21} X_{1}+A_{22} X_{2}+\cdots+A_{2 n} X_{n}+X_{n+3}-X_{n+4}=\mathrm{Al}_{2} \mathrm{O}_{3}
\end{aligned}
$$

$$
\begin{aligned}
& A_{m 1} X_{1}+A_{m 2} X_{2}+\cdots+A_{m n} X_{n}+X_{n+2 m-1}-X_{n+2 m}=b_{m} \\
& X_{1}, X_{2}, \ldots, X_{n}, X_{n+1}, \ldots, X_{n+2 m} \geq 0 .
\end{aligned}
$$

According to the method for solving linear equations, the amounts of each mineral in a soil and their residual errors can be obtained.

\section{Calculation procedures}

\subsection{Choice of oxides}

The contents of $\mathrm{MnO}, \mathrm{TiO}_{2}$, and $\mathrm{P}_{2} \mathrm{O}_{5}$ in soil samples are quite low, and exert little constraint on the calculation. Moreover, the analytical precision on these oxides is low, which may affect the accuracy of the calculation. The LOI (loss on ignition) is contributed by several phases in samples, such as the organic matter, carbonate, and $\mathrm{H}_{2} \mathrm{O}$ in clay minerals (e.g., kaolinite, montmorillonite, and illite). As the content of organic matter is unknown, it is hard to estimate the contribution of LOI from each phase. So these phases will not be considered in the calculation. During the sample preparation process, $\mathrm{Fe}^{2+}$ may turn into $\mathrm{Fe}^{3+}$, which changes the actual contents of $\mathrm{Fe}_{2} \mathrm{O}_{3}$ and $\mathrm{FeO}$. Therefore, we take the sum of $\mathrm{Fe}_{2} \mathrm{O}_{3}$ and $\mathrm{FeO}$ as TFe (total iron). Consequently, we use $\mathrm{SiO}_{2}, \mathrm{Al}_{2} \mathrm{O}_{3}, \mathrm{CaO}, \mathrm{Na}_{2} \mathrm{O}$, $\mathrm{K}_{2} \mathrm{O}, \mathrm{MgO}$, and $\mathrm{TFe}$ as variables for the calculation.

\subsection{Estimation of mineral phases}

The number of mineral phases in soil controls the number of variables in the equation. The mineral phases can be obtained from data available in the literature or by qualitative analysis with XRD.

\subsection{Chemical composition of minerals (Construction of the matrix A)}

Chemical compositions of minerals with complex components such as those of biotite, kaolinite, illite, and montmorillonite can be determined by taking the respective averages of several analyses. Minerals such as calcite, Fe-Mn colloids, and quartz with simpler components can be assumed to have compositions suggested by their empirical formulas. For feldspar, after decomposing into three end members (An, Ab and Or), the oxide content of each end member are calculated according to their molecular formulae. The above parameters and the coefficients for the residual errors constitute the matrix A.

Mole percentages of the Or, Ab and An components of plagioclase were estimated. Using the phase diagram of Rittmann and Gottini (1973), these values were recast into a K-feldspar component and a plagioclase component, having composition corresponding to the values of the $\mathrm{Ab}$ and 
An components. Finally, the results were converted into mass percentages.

\subsection{Example}

The samples used for demonstrating the calculation methodology adopted here were collected from Daxinganling, located in the frigid alpine region of northeast China. The rocks of this area have undergone more physical weathering compared to chemical weathering. Chemical compositions of the samples are listed in table 1 . Some researchers have concluded that primary minerals in soils of this region are mainly quartz, plagioclase, K-feldspar, and small amount of biotite; secondary minerals are mainly montmorillonite, illite, and kaolinite (Ma et al. 2003; Hao et al. 2004). It is supported by XRD qualitative analysis. Based on the parameters listed in table 2 and equation (3), using the function 'linprog' in the optimization toolbox of Matlab 7.0, we obtained the contents of the minerals in soil samples. The calculated results are listed in table 3.

\section{Results and discussion}

The results calculated from this method have high accuracy (total residual errors $<1.29 \mathrm{E}-09$ ). A high match between the calculated and observed mineralogy of the soil samples was obtained. Synthetic samples produced by mixing standard minerals in known proportions were processed to check the reliability of the method (table 4). The RSD (relative standard deviation) of the results are $<2 \%$.
For comparison, we determined mineral contents of the samples with X-ray diffraction quantitative analysis. The results are presented in table 5 . The comparison shows that the contents of quartz and feldspar calculated by the optimization method are lower than those determined by X-ray diffraction analysis, while the contents of clay minerals are higher than those obtained by X-ray diffraction analysis, especially kaolinite and illite.

To investigate the differences between the two methods above, we calculated back the contents of the oxides in the soil samples from the mineral composition given by X-ray diffraction analysis. However, the calculated $\mathrm{SiO}_{2}$ contents are much higher than that obtained by chemical analysis. It demonstrates that the felsic primary mineral contents determined by X-ray diffraction analysis are higher than their actual contents, while the clay mineral contents are lower. The sample preparation method may be an important factor that affects the accuracy of X-ray diffraction analysis (Chen et al. 1998). Chen et al. (1998) concluded that particle sizes of clay minerals may affect the estimation of their relative and absolute contents. The absolute contents of clay minerals show a significant increase with the increasing particle size: when the particle sizes increase from 2 to $37 \mu \mathrm{m}$, the absolute contents of clay minerals increase from $1.56 \%$ to $>7.85 \%$ (Chen et al. 1998). The soil samples in our research are incompletely weathered with a certain amount of residual primary minerals. The clay minerals (especially kaolinite) that exist in the fracture or the cleavage planes of the primary mineral particles are difficult to separate. Consequently, the contents of clay minerals determined by $\mathrm{X}$ ray diffraction analysis would be lower, while the

Table 1. Chemical composition of soils (wt\%).

\begin{tabular}{lccccccccccrrr}
\hline & & & & & & & & & & & \\
Sample & $\mathrm{SiO}_{2}$ & $\mathrm{TiO}_{2}$ & $\mathrm{Al}_{2} \mathrm{O}_{3}$ & $\mathrm{Fe}_{2} \mathrm{O}_{3}$ & $\mathrm{FeO}$ & $\mathrm{MnO}$ & $\mathrm{MgO}$ & $\mathrm{CaO}$ & $\mathrm{Na}_{2} \mathrm{O}$ & $\mathrm{K}_{2} \mathrm{O}$ & $\mathrm{P}_{2} \mathrm{O}_{5}$ & $\begin{array}{c}\text { ignition } \\
\text { igotal }\end{array}$ \\
\hline 1 & 61.24 & 1.35 & 13.48 & 5.71 & 3.25 & 0.15 & 0.92 & 0.89 & 1.73 & 2.00 & 0.13 & 9.12 & 99.97 \\
2 & 64.72 & 1.04 & 16.31 & 4.54 & 1.05 & 0.07 & 1.58 & 1.05 & 2.42 & 2.59 & 0.08 & 4.46 & 99.91 \\
3 & 68.88 & 1.00 & 13.44 & 0.18 & 1.67 & 0.02 & 0.72 & 0.81 & 1.91 & 2.79 & 0.07 & 8.76 & 100.25 \\
4 & 65.96 & 0.86 & 14.96 & 2.19 & 1.57 & 0.13 & 0.93 & 0.79 & 1.55 & 2.86 & 0.08 & 8.35 & 100.23 \\
5 & 68.78 & 0.70 & 13.85 & 0.18 & 1.52 & 0.03 & 0.56 & 0.72 & 2.23 & 2.48 & 0.07 & 9.35 & 100.47 \\
6 & 60.70 & 0.83 & 17.48 & 3.74 & 1.82 & 0.10 & 1.28 & 1.51 & 2.32 & 2.69 & 0.14 & 7.85 & 100.46 \\
7 & 61.76 & 0.90 & 18.50 & 4.88 & 0.81 & 0.13 & 1.50 & 0.84 & 2.97 & 2.43 & 0.22 & 4.14 & 99.48 \\
8 & 56.92 & 0.84 & 19.32 & 3.56 & 1.77 & 0.09 & 1.38 & 2.70 & 2.71 & 2.64 & 0.16 & 7.41 & 99.60 \\
9 & 65.40 & 0.65 & 15.84 & 2.32 & 1.31 & 0.14 & 0.98 & 1.23 & 2.42 & 3.53 & 0.08 & 6.16 & 100.06 \\
10 & 69.16 & 0.67 & 15.38 & 2.87 & 0.94 & 0.05 & 0.71 & 0.68 & 3.19 & 3.32 & 0.08 & 2.95 & 100.00 \\
11 & 62.80 & 0.68 & 17.88 & 3.80 & 0.53 & 0.07 & 0.73 & 0.61 & 2.73 & 2.87 & 0.20 & 7.50 & 100.40 \\
12 & 64.38 & 0.87 & 18.03 & 4.31 & 0.04 & 0.04 & 1.06 & 0.64 & 1.62 & 3.4 & 0.06 & 6.17 & 100.32 \\
13 & 65.82 & 0.84 & 17.27 & 3.12 & 1.08 & 0.03 & 1.04 & 0.65 & 1.76 & 3.67 & 0.04 & 4.75 & 100.07 \\
14 & 69.80 & 1.18 & 15.23 & 2.77 & 0.27 & 0.03 & 0.82 & 0.55 & 2.12 & 2.81 & 0.09 & 5.29 & 100.32 \\
15 & 66.50 & 0.85 & 16.25 & 4.04 & 0.06 & 0.03 & 1.11 & 0.67 & 1.91 & 3.80 & 0.09 & 4.84 & 100.15 \\
16 & 65.46 & 0.75 & 17.75 & 3.72 & 0.27 & 0.03 & 1.12 & 0.60 & 2.01 & 3.96 & 0.06 & 4.32 & 100.05 \\
\hline
\end{tabular}

Lab of analysis: Testing Center, Jilin University. 
Table 2. Chemical composition of minerals.

\begin{tabular}{lccccccc}
\hline & $\mathrm{SiO}_{2}$ & $\mathrm{Al}_{2} \mathrm{O}_{3}$ & $\mathrm{CaO}$ & $\mathrm{Na}_{2} \mathrm{O}$ & $\mathrm{K}_{2} \mathrm{O}$ & $\mathrm{MgO}$ & $\mathrm{TFe}$ \\
\hline Calcite & 0.00 & 0.00 & 0.54 & 0.00 & 0.00 & 0.00 & 0.00 \\
Colloid & 0.00 & 0.00 & 0.00 & 0.00 & 0.00 & 0.00 & 1.00 \\
Quartz & 1.00 & 0.00 & 0.00 & 0.00 & 0.00 & 0.00 & 0.00 \\
$\mathrm{An}$ & 0.43 & 0.37 & 0.20 & 0.00 & 0.00 & 0.00 & 0.00 \\
$\mathrm{Ab}$ & 0.69 & 0.19 & 0.00 & 0.12 & 0.00 & 0.00 & 0.00 \\
Or & 0.65 & 0.18 & 0.00 & 0.00 & 0.17 & 0.00 & 0.00 \\
Biotite (Hao Libo 1990) & 0.36 & 0.16 & 0.01 & 0.01 & 0.08 & 0.10 & 0.21 \\
Kaolinite (Kedev 1981) & 0.45 & 0.39 & 0.00 & 0.01 & 0.00 & 0.00 & 0.00 \\
Illite (Kedev 1981) & 0.49 & 0.29 & 0.01 & 0.00 & 0.07 & 0.01 & 0.03 \\
Montmorillonite (Kedev 1981) & 0.51 & 0.20 & 0.02 & 0.00 & 0.00 & 0.03 & 0.01 \\
\hline
\end{tabular}

Table 3. Calculated mineral contents in soil samples (wt\%).

\begin{tabular}{lcrrrrrrrr}
\hline Sample & Q & Pl & \multicolumn{1}{c}{ Kf } & Bi & Cc & Colloid & Kao & Ill & Mm \\
\hline 1 & 31.53 & 15.27 & 6.09 & 4.36 & 0.40 & 7.64 & 9.97 & 8.19 & 11.04 \\
2 & 27.18 & 22.24 & 4.71 & 9.69 & 0.56 & 3.09 & 10.22 & 8.85 & 14.23 \\
3 & 36.73 & 14.57 & 13.86 & 3.00 & 0.44 & 0.85 & 8.37 & 7.68 & 9.43 \\
4 & 33.32 & 10.80 & 12.60 & 4.40 & 0.40 & 2.36 & 12.09 & 10.05 & 10.39 \\
5 & 36.11 & 19.22 & 10.75 & 2.02 & 0.35 & 0.92 & 10.26 & 7.28 & 7.69 \\
6 & 22.36 & 20.35 & 8.48 & 7.30 & 1.04 & 3.54 & 13.29 & 9.67 & 12.13 \\
7 & 20.06 & 30.27 & 0.01 & 8.94 & 0.34 & 3.31 & 14.70 & 9.15 & 13.89 \\
8 & 14.68 & 25.86 & 7.78 & 7.76 & 2.36 & 3.18 & 13.41 & 10.02 & 13.61 \\
9 & 26.84 & 19.00 & 16.70 & 5.26 & 0.86 & 2.10 & 8.25 & 9.57 & 9.50 \\
10 & 28.99 & 29.38 & 12.45 & 3.49 & 0.31 & 2.72 & 7.33 & 8.10 & 7.39 \\
11 & 23.10 & 25.73 & 7.57 & 3.50 & 0.31 & 3.11 & 16.93 & 10.24 & 6.88 \\
12 & 27.43 & 9.36 & 15.60 & 6.19 & 0.31 & 2.52 & 19.55 & 10.51 & 8.34 \\
13 & 28.15 & 10.50 & 17.35 & 5.61 & 0.31 & 2.49 & 15.08 & 11.64 & 9.23 \\
14 & 34.96 & 18.20 & 9.82 & 3.76 & 0.23 & 1.80 & 12.05 & 9.41 & 9.29 \\
15 & 28.79 & 12.02 & 18.14 & 6.08 & 0.28 & 2.32 & 10.83 & 11.23 & 10.17 \\
16 & 25.54 & 12.38 & 18.69 & 6.32 & 0.25 & 2.13 & 14.26 & 11.87 & 9.37 \\
\hline
\end{tabular}

Note. Q: Quartz, Pl: Plagioclase, Kf: K-feldspar, Bi: Biotite, Cc: Carbonate, Kao: Kaolinite, Ill: Illite, Mm: Montmorillonite.

Table 4. Synthetic mixture compositions compared with the calculated results (wt\%).

\begin{tabular}{|c|c|c|c|c|c|c|c|c|c|c|c|c|c|c|c|}
\hline & \multicolumn{3}{|c|}{ Synthetic mixtures } & \multicolumn{12}{|c|}{ Minerals content determined by calculation } \\
\hline & $\overline{\mathrm{KaO}}$ & Ill & $\mathrm{Mm}$ & $\overline{\mathrm{Q}}$ & $\mathrm{Kf}$ & $\mathrm{Pl}$ & $\mathrm{Bi}$ & $\mathrm{Cc}$ & Colloid & Kao & RSD & Ill & RSD & $\mathrm{Mm}$ & RSD \\
\hline 1 & 100 & 0 & 0 & 0 & 0 & 0 & 0 & 0 & 0 & 100 & 0 & 0 & 0 & 0 & 0 \\
\hline 3 & 0 & 0 & 100 & 0 & 0 & 0 & 0 & 0 & 0 & 0 & 0 & 0 & 0 & 100 & 0 \\
\hline 2 & 0 & 60 & 40 & 0 & 0 & 0.04 & 0 & 0 & 0 & 0.49 & - & 60.00 & 0 & 39.54 & 1.15 \\
\hline 6 & 60 & 0 & 40 & 0 & 0 & 0.05 & 0 & 0 & 0 & 60.73 & 1.21 & 0.00 & 0 & 39.31 & 1.73 \\
\hline 4 & 0 & 50 & 50 & 0 & 0 & 0.03 & 0 & 0 & 0 & 0.41 & - & 50.00 & 0 & 49.61 & 1.00 \\
\hline 5 & 50 & 0 & 50 & 0 & 0 & 0.04 & 0 & 0 & 0 & 50.61 & 1.22 & 0.00 & 0 & 49.42 & 1.16 \\
\hline
\end{tabular}

RSD is relative standard deviation.

contents of felsic minerals would be higher. The above problems hardly affect the results obtained by our method, which is based on the original chemical composition of the soil sample. The results on the clay minerals represent the total contents without distinguishing the different occurrences thereof.

To test the effect of varying parameters on the accuracy of this approach, we compared the calculations by varying the matrix $\mathrm{A}$. In this paper, the chemical compositions of kaolinite, illite, and montmorillonite reported by Kedev (1981) were used to construct the matrix A. We constructed the matrix A with different parameters reported by Chen and Wang (2004). Compared with the results in table 3 , the relative errors for kaolinite, illite, and montmorillonite are $13 \%, 16 \%$, and $16 \%$, respectively. 
Table 5. Mineral contents determined by X-ray diffraction analysis (wt\%).

\begin{tabular}{lrrrrrrrrrrrrrrrrr}
\hline Sample & 1 & 2 & 3 & 4 & 5 & 6 & 7 & 8 & 9 & 10 & 11 & 12 & 13 & 14 & 15 & 16 \\
\hline Quartz & 45 & 34 & 52 & 55 & 37 & 38 & 30 & 27 & 48 & 40 & 39 & 47 & 44 & 52 & 42 & 44 \\
Plagioclase & 22 & 32 & 17 & 15 & 17 & 27 & 31 & 25 & 18 & 32 & 25 & 20 & 16 & 17 & 11 & 18 \\
K-feldspar & 10 & 12 & 12 & 10 & 14 & 16 & 18 & 17 & 12 & 14 & 11 & 12 & 17 & 11 & 29 & 19 \\
Kaolinite & 3 & 5 & 4 & 4 & 3 & 5 & 3 & 3 & 6 & 3 & 4 & 4 & 6 & 4 & 4 & 5 \\
Mixed-layer of Ill and Mm & 13 & 9 & 8 & 9 & 18 & 10 & 11 & 19 & 7 & 5 & 11 & 9 & 7 & 7 & 7 & 7 \\
Illite & 6 & 6 & 7 & 7 & 11 & 4 & 6 & 7 & 7 & 6 & 10 & 8 & 10 & 9 & 7 & 7 \\
\hline
\end{tabular}

Lab of analysis: Testing Center, Jilin University.

There are multiple methods of getting solutions to equations and different software packages offer similar options but do not give identical solutions (Yong 2007). We have compared different software packages with similar options. The solutions given by Excel and Lingo show that contents of the feldspar end members and some of the clay minerals in soils are zero, which is not in accordance with the factual situation. The XRD analysis indicates that all of the samples have a certain amount of kaolinite, illite, and montmorillonite. By contrast, Matlab gives a better solution. Therefore, we recommend employing Matlab to solve equations of the kind discussed here.

In conclusion, using optimization methods to calculate the clay mineral contents in soil is viable based on the chemical analysis data. Further studies combining this method with X-ray diffraction, differential thermal, and infrared spectrometry analysis are clearly necessary.

\section{Acknowledgements}

This work was supported by research grants from the China Geological Survey (SinoProbe-04-05-03 and 20089941). Our sincere thanks go to Anindya Sarkar and Kamal L Pruseth for their valuable comments and suggestions, which have improved the paper significantly.

\section{References}

Baldock J A and Skjemstad J O 2000 Role of the soil matrix and minerals in protecting natural organic materials against biological attack; Org. Geochem. 31 697-710.

Brennan F P, Moynihan E, Griffiths B S, Hillier S, Owen J, Pendlowski H and Avery L M 2014 Clay mineral type effect on bacterial enteropathogen survival in soil; Sci. Total Environ. 468 302-305.

Chen R J and Han Z Y 1998 Estimation and calculation of the character-show mineral composition in the clay materials; Hebei Ceramics 26(1) 10-18 (in Chinese with English abstract).
Chen J and Wang H N 2004 Geochemistry; (Beijing, China: Science Press), pp. 285-289 (in Chinese).

Chen Z, Shen M D and Zhao J S 1998 Problems on quantitative analysis of clay minerals; Acta Sedimentologica Sinca 16(1) 137-139 (in Chinese with English abstract).

Chung F H 1974a Quantitative of X-ray diffraction patterns of mixture. I. Matrix-Flushing Method for quantitative multicomponent analysis; J. Appl. Cryst. 7 519-526.

Chung F H 1974b Quantitative interpretation of X-ray diffraction patterns of mixtures. II. Adiabatic principle of X-ray diffraction analysis of mixtures; J. Appl. Cryst. 7 526-531 (in Chinese).

Ding P M and Zhang Q L 2002 X-ray diffraction analysis of minerals in soil and its applications on geo-environmental engineering; J. Qingdao I Archit Eng. 23(1) 12-15 (in Chinese with English abstract).

Fateer M A 1969 The distribution of clay minerals in the ocean; Sedimentology 13 21-43.

Griffi J J 1968 The distribution of clay minerals in the world ocean; Deep-See Res. 15 433-459.

Hao L B 1990 A new method of calculating mineral content linear programming; Miner and Rocks 10(2) 97-101 (in Chinese with English abstract).

Hao L B, Ma L and Zhao H B 2004 Elemental homogenization during weathering and pedogenesis of volcanic rocks from North Da Hinggin Ling; Geochemica 33(2) 131-138 (in Chinese with English abstract).

Kedev V A 1981 Theory of soil; (Beijing, China: Science Press), pp. 208-209.

Li Y S and Li Y 1995 The analysing and microcomputerisation of clay mineral composition; Ceram Studies J. 10(4) 201-206 (in Chinese with English abstract).

Liao L B 1995 Study of calculation methods for X-ray quantitative analysis of clay minerals; Geoscience 19(4) 423-425 (in Chinese with English abstract).

Lichner L, Dlapa P, Doerr S H and Mataix-Solera J 2006 Evaluation of different clay minerals as additives for soil water repellency alleviation; Appl. Clay Sci 31(3) $238-248$.

Ma L, Hao L B and Pan J 2003 Geochemistry of rhyolite weathering of Alongshang, Greater Xing'an mountains; J. Jilin Univ. (Earth Science edn) 30(3) 296-314 (in Chinese with English abstract).

Mitchell J K 1993 Fundamentals of soil behavior; Willey Publishing, pp. 230-235.

Rittmann A and Gottini V 1973 Stable mineral assemblages of igneous rocks: A method of calculation (Heidelberg, New York: Springer), pp. 74-87.

Singh V and Agrawal H M 2012 Qualitative soil mineral analysis by EDXRF, XRD and AAS probes; Radiation Physics and Chemistry 81(12) 1796-1803.

Tang Y J, Jia J Y and Xie X D 2002 Environment significance of clay minerals; Earth Sci. Front 9(2) 337-344 (in Chinese with English abstract). 
Wu Q R 1994 Phase analysis of clay minerals by X-ray diffraction; Rock Miner. Anal. 13(1) 15-19 (in Chinese with English abstract).

Wu Q R 1996 The application of preferred orientation of crystallographic plane in phase quantitative analysis of clay minerals by X-ray diffraction; Rock Miner. Anal. 15(2) 147-149 (in Chinese with English abstract).
Yong L Q 2007 Some methods for solving linear programming; Jiangxi Science 25(2) 201-212 (in Chinese with English abstract).

Zhang R K and Fan G 2003 Quantitative analytic method and experiments of X-ray diffraction phase of clay minerals; Uranium Geology 10(3) 180-185 (in Chinese with English abstract). 